\title{
Transepithelial corneal collagen cross-linking in ultrathin keratoconic corneas
}

\author{
Leopoldo Spadea' \\ Rita Mencucci ${ }^{2}$ \\ 'University of L'Aquila, Department \\ of Biotechnological and Applied \\ Clinical Sciences, Eye Clinic, L’Aquila, \\ ${ }^{2}$ University of Florence, Department \\ of Oto-Neuro-Ophthalmological \\ Surgical Sciences, Eye Clinic, \\ Florence, Italy
}

This article was published in the following Dove Press journal:

Clinical Ophthalmology

31 October 2012

Number of times this article has been viewed

Background: The purpose of this paper was to report the results of transepithelial corneal collagen cross-linking (CXL) with modified riboflavin and ultraviolet A irradiation in patients affected by keratoconus, each with thinnest pachymetry values of less than $400 \mu \mathrm{m}$ (with epithelium) and not treatable using standard de-epithelialization techniques.

Methods: Sixteen patients affected by progressive keratoconus with thinnest pachymetry values ranging from $331 \mu \mathrm{m}$ to $389 \mu \mathrm{m}$ underwent transepithelial CXL in one eye using a riboflavin $0.1 \%$ solution in $15 \%$ Dextran T500 containing ethylenediamine tetra-acetic acid $0.01 \%$ and trometamol to enhance epithelial penetration. The patients underwent complete ophthalmological examination, including endothelial cell density measurements and computerized videokeratography, before CXL and at one day, one week, and one, 6, and 12 months thereafter.

Results: Epithelial healing was complete in all patients after one day of use of a soft bandage contact lens. No side effects or damage to the limbal region was observed during the follow-up period. All patients showed slightly improved uncorrected and spectacle-corrected visual acuity; keratometric astigmatism showed reductions (up to $5.3 \mathrm{D}$ ) and apical ectasia power decreased $\left(\mathrm{K}_{\max }\right.$ values reduced up to $\left.4.3 \mathrm{D}\right)$. Endothelial cell density was unchanged.

Conclusion: Application of transepithelial CXL using riboflavin with substances added to enhance epithelial permeability was safe, seemed to be moderately effective in keratoconic eyes with ultrathin corneas, and applications of the procedure could be extended to patients with advanced keratoconus.

Keywords: keratoconus, pachymetry, topography, transepithelial corneal collagen crosslinking, thin cornea

\section{Introduction}

Corneal collagen cross-linking (CXL) with riboflavin and ultraviolet $\mathrm{A}$ is a technique used to strengthen corneal tissue with riboflavin as a photosensitizer and ultraviolet A to increase the formation of covalent intrafibrillar and interfibrillar bonds by photosensitized oxidation. ${ }^{1}$ This parasurgical technique may reduce corneal steepening, potentially stabilizing the cornea, and improve the refractive error by minimizing irregular astigmatism induced as a result of biomechanical instability of the cornea. The major indication for CXL is to inhibit progression of corneal ectasia, such as keratoconus and pellucid marginal degeneration. ${ }^{1-3}$ In recent years, corneal ectasia has also been documented quite frequently secondary to photorefractive keratectomy and laser-assisted in situ keratomileusis procedures, characterized by progressive corneal thinning associated with loss of uncorrected and often corrected distance visual acuity. ${ }^{4,5}$
Correspondence: Leopoldo Spadea Via Benozzo Gozzoli 34, 00142

Rome, Italy

Tel +3908 6231 967।

Fax +390862434958

Email Ispadea@cc.univaq.it 
Nowadays, CXL is limited to eyes with a corneal thickness of at least $400 \mu \mathrm{m}$ due to concerns about the cytotoxic effect on the endothelium, crystalline lens, and other intraocular tissues. ${ }^{6,7}$ This threshold has limited its performance in eyes with advanced stages of corneal ectasia. The downside of current pachymetric is that patients with keratoconus or keratectasia often have corneas that are thinner than the $400 \mu \mathrm{m}$ threshold. Transepithelial CXL, ${ }^{8} \mathrm{CXL}$ with customized pachymetric-guided epithelial debridement to preserve the epithelium in thinner corneal regions, ${ }^{9}$ and the concept of iatrogenic corneal swelling before $\mathrm{CXL}$ application ${ }^{10}$ have each been developed as alternative techniques for thin corneas.

The accepted protocol for CXL entails de-epithelialization prior to topical administration of riboflavin, which is a macromolecule and therefore cannot penetrate intact epithelium in adequate concentrations to achieve CXL. ${ }^{11}$ However, epithelial permeability can be enhanced by several topical drugs, including benzalkonium chloride and ethylenediamine tetra-acetic acid (EDTA). ${ }^{12-14}$ The second remarkable challenge of transepithelial CXL lies in the ability of the epithelium to absorb ultraviolet A radiation targeted to the stroma. ${ }^{15}$ In order to investigate the safety and efficacy of transepithelial CXL in keratoconic patients with ultrathin corneas, we performed CXL without de-epithelialization using a modified riboflavin photosensitizer in $15 \%$ Dextran T500 with EDTA $0.01 \%$ and trometamol to enhance epithelial penetration.

\section{Materials and methods}

The present study was approved by the institutional ethics committee for patients with progressive keratoconus and corneal thicknesses of less than $400 \mu \mathrm{m}$ (with epithelium). Sixteen patients intolerant of contact lenses and affected by progressive keratoconus with corneal pachymetry under $400 \mu \mathrm{m}$ at the area of topographic steepening underwent transepithelial CXL between June 2009 and January 2012 at the Eye Clinic of L'Aquila University and at the Eye Clinic of Florence University. Inclusion criteria were keratoconus with documented progression in the past 12 months, and corneal thickness less than $400 \mu \mathrm{m}$ at the thinnest point. Progression was defined as an increase in maximum keratometry (K) of 1.00 diopter (D) or more in the previous 12 months and patient-reported deterioration of visual acuity (excluding other possible noncorneal-related reasons for deterioration). ${ }^{16}$

Exclusion criteria were corneal opacity, previous herpetic keratitis, previous ocular surgery, active ocular infection, autoimmune disease, diabetes, pregnancy, and lactation. Smokers were also excluded because of the presumed negative association between smoking and progression of keratoconus. ${ }^{17}$ Keratoconus was diagnosed using a combination of computerized videokeratography (Keratograph, Oculus Optikgeräte GmbH, Wetzlar, Germany), and ultrasound pachymetry (Corneo Gage ${ }^{\mathrm{TM}}$ Plus, Sonogage Inc, Cleveland, OH). Although corneal pachymetry was always under 400 microns at the area of topographic steepening ( $331 \mu \mathrm{m}$ to $389 \mu \mathrm{m}$ as measured by ultrasound pachymetry), central corneal pachymetries were between $430 \mu \mathrm{m}$ and $445 \mu \mathrm{m}$. The patients underwent a complete ophthalmologic examination, including noncontact endothelial specular microscopy (Seed SP500, Seed Co, Tokyo, Japan) analysis (Table 1).

Table I Mean preoperative and postoperative data for patients who had transepithelial corneal collagen cross-linking

\begin{tabular}{|c|c|c|c|}
\hline & $\begin{array}{l}\text { Preoperative } \\
(n=16)\end{array}$ & $\begin{array}{l}6 \text { months } \\
(n=16)\end{array}$ & $\begin{array}{l}\text { I } 2 \text { months } \\
(\mathrm{n}=7)\end{array}$ \\
\hline \multicolumn{4}{|c|}{ UDVA (logMAR) } \\
\hline Mean \pm SD & $0.95 \pm 0.45$ & $0.61 \pm 0.45$ & $0.74 \pm 0.38$ \\
\hline Range & $0.2-1.3$ & $0.2-1.3$ & $0.1-1.0$ \\
\hline$P$ value & & 0.015 & 0.295 \\
\hline \multicolumn{4}{|c|}{ CDVA (logMAR) } \\
\hline Mean \pm SD & $0.37 \pm 0.27$ & $0.33 \pm 0.30$ & $0.34 \pm 0.31$ \\
\hline Range & $0.1-1.0$ & $0.0-1.0$ & $0.0-1.0$ \\
\hline$P$ value & & 0.695 & 0.817 \\
\hline \multicolumn{4}{|l|}{ MRSE (D) } \\
\hline Mean \pm SD & $-3.27 \pm 2.83$ & $-2.97 \pm 2.98$ & $-2.95 \pm 2.96$ \\
\hline Range & $-10.0-0.50$ & $-11.0-0.25$ & $-10.5-0.25$ \\
\hline$P$ value & & 0.772 & 0.870 \\
\hline \multicolumn{4}{|c|}{ Average Sim K (D) } \\
\hline Mean \pm SD & $49.38 \pm 3.46$ & $46.95 \pm 2.99$ & $48.37 \pm 2.90$ \\
\hline Range & $43.6-55.6$ & $44.2-53.6$ & $44.0-53.4$ \\
\hline$P$ value & & 0.042 & 0.508 \\
\hline \multicolumn{4}{|l|}{ Kapex (D) } \\
\hline Mean \pm SD & $61.30 \pm 7.26$ & $56.10 \pm 5.20$ & $58.21 \pm 6.20$ \\
\hline Range & $52.0-78.0$ & $50.4-75.0$ & $50.2-67.3$ \\
\hline$P$ value & & 0.027 & 0.339 \\
\hline \multicolumn{4}{|c|}{ Corneal thickness $(\mu \mathrm{m})$} \\
\hline Mean \pm SD & $369.6 \pm 19.2$ & $365.4 \pm 21.1$ & $367.7 \pm 21.3$ \\
\hline Range & $331-389$ & $330-385$ & $33 I-387$ \\
\hline$P$ value & & 0.579 & 0.826 \\
\hline \multicolumn{4}{|c|}{$\mathrm{ECD}\left(\right.$ cells $\left./ \mathrm{mm}^{2}\right)$} \\
\hline Mean \pm SD & $2213.4 \pm 105$ & $2204.4 \pm 110$ & $2202.1 \pm 108$ \\
\hline Range & $1954-2367$ & $1939-2379$ & $1930-2380$ \\
\hline$P$ value & & 0.814 & 0.821 \\
\hline \multicolumn{4}{|c|}{ Corneal endothelial CoV (SD cell area/mean cell area) } \\
\hline Mean \pm SD & $28.2 \pm 5$ & $29.0 \pm 8$ & $29.1 \pm 7$ \\
\hline Range & $23-28$ & $23-33$ & $23-32$ \\
\hline$P$ value & & 0.737 & 0.728 \\
\hline
\end{tabular}

Abbreviations: UDVA, uncorrected distance visual acuity; CDVA, corrected distance visual acuity; logMAR, logarithm of the minimum angle of resolution; MRSE, manifest refractive spherical equivalent; Kapex, curvature at corneal apex on tangential map; AveSimK, average of simulated keratometry values; ECD, endothelial cell density; CoV, coefficient of variation; SD, standard deviation. 
The risks, benefits, and alternatives to this procedure were explained to the patient, including a clear disclosure that this procedure was experimental. The patient signed an informed consent for the modified CXL procedure as an attempt to block progression of ectasia and minimize the chances of complications that would be associated with more invasive surgical treatment. One patient with advanced keratoconus and cataract, after providing informed consent, agreed to the transepithelial CXL procedure being performed before penetrating keratoplasty and cataract extraction, allowing us to study the histological and immunohistochemical findings.

Transepithelial CXL induced by riboflavin and ultraviolet A radiation was performed under sterile conditions as follows:

- Riboflavin $0.1 \%$ solution in $15 \%$ Dextran T500 containing sodium EDTA $0.01 \%$ and trometamol (Ricrolin TE ${ }^{\circledR}$, Sooft, Montegiorgio, Italy) was instilled every 10 minutes for 2 hours.

- Topical anesthesia was provided by oxybuprocaine $0.4 \%$ eye drops preserved with p-hydroxybenzoate (Benoxinato Cloridrato, Alfa Intes, Naples, Italy) instilled every 5 minutes for 15 minutes.

- One drop of pilocarpine $1 \%$ was then instilled to constrict the pupil and reduce ultraviolet $\mathrm{A}$ irradiation to the lens and retina.

- An eyelid speculum was inserted and riboflavin was instilled over the cornea every 3 minutes for 15 minutes.

- Ultraviolet A irradiation was delivered using a CBM Vega X-Linker device (CBM X-linker, CSO, Florence, Italy). The device was calibrated to $3.0 \mathrm{~mW} / \mathrm{cm}^{2}$ of surface irradiance $\left(5.4 \mathrm{~J} / \mathrm{cm}^{2}\right.$ surface dose) using an ultraviolet light meter at the specified working distance. Ultraviolet A irradiation was applied to the central $9 \mathrm{~mm}$ of the cornea for 30 minutes, and the riboflavin solution was instilled every 5 minutes. The aiming beam was focused on the central cornea, while the patient fixated on a pulsating green light.

At the end of the procedure, the eye was rinsed with balanced salt solution and a therapeutic bandage soft contact lens was applied. An antibiotic regimen of ofloxacin and flurbiprofen drops was administered four times a day for one week. Topical corticosteroid (clobetasone butyrate $0.1 \%$ ) drops were then administered for one month and subsequently tapered.

The treated eyes were examined one day (when the bandage contact lenses were removed), one week, and one, 3, 6, and 12 months after treatment. A complete ophthalmological examination was performed at each visit, and included uncorrected and corrected distance visual acuity, intraocular pressure measurement (Goldmann applanation tonometer), anterior segment and fundus slit-lamp examination, endothelial cell density assessment, and computerized videokeratography.

To evaluate histological and immunohistochemical findings after transepithelial CXL in thin corneas, we studied the oldest patient who underwent the triple procedure of penetrating keratoplasty, open-sky extracapsular cataract extraction, and intraocular lens insertion 6 months after transepithelial CXL. The host bed was trephined, and an $8.25 \mathrm{~mm}$ donor button was sutured into a $8.00 \mathrm{~mm}$ recipient bed with a 16-bite single running 10-0 nylon suture. The explanted cornea was sent for examination, and the results have been reported previously. ${ }^{18}$

\section{Results}

Sixteen eyes from 16 patients (eight men, eight women) with keratoconus were included in the study. The mean age of the patients was $34.4 \pm 11.9$ (range 18-61) years. All patients attended the 6-month follow-up. One-year follow-up results were available for seven patients. All procedures were uneventful and no intraoperative complications were observed. No damage to the limbal region of any patient was observed. The epithelium was completely healed within one day after treatment (Figure 1) in all patients. Intraocular pressures evaluated by Goldmann applanation tonometry were less than $18 \mathrm{mmHg}$ in all eyes. Fundus examinations were within normal limits. In the treated eyes, the corneal thicknesses and the endothelial cell densities and morphologies

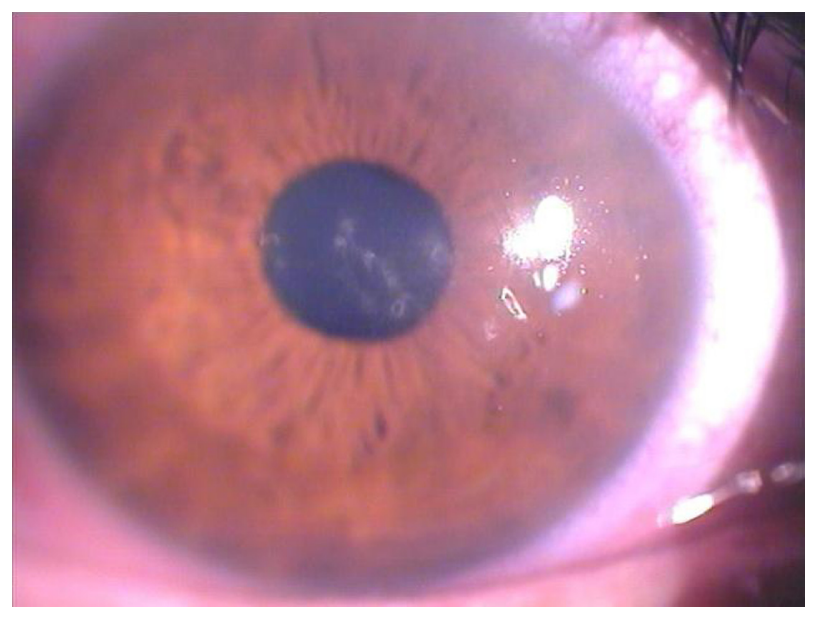

Figure I Biomicroscopic image of the right eye of a 27 -year-old male patient one day after corneal collagen cross-linking with riboflavin and ultraviolet A irradiation. Note: The epithelium shows some superficial irregularity, but the overall cornea appears very clear. 
were unchanged between baseline and the 6-month and 12-month assessments (Table 1). Slit-lamp observations just before ultraviolet A irradiation did not reveal any significant biomicroscopic epithelial abnormalities. Yellow particle diffusion in the anterior chamber was not apparent using cobalt blue light. There were no toxic effects or complications observed during re-epithelialization or during the follow-up period in the treated eyes.

At the last postoperative visit, computerized videokeratography showed a small mean reduction in the curvature of apical ectasia ( $\mathrm{K}_{\max }$ values reduced up to $\left.4.3 \mathrm{D}\right)$ and in keratometric astigmatism (reduced up to 5.3, Figure 2) in all patients, while noncontact endothelial specular microscopy analysis demonstrated no significant corneal endothelial cell changes, either in quantity and quality. The central corneal thickness remained stable to $\pm 10 \mu \mathrm{m}$ in all patients. Both uncorrected and corrected distance visual acuity showed a slight improvement (up to three lines) of mean visual acuity (logarithm of the minimum angle of resolution [logMAR]) and a small reduction in mean manifest spherical equivalent refraction (up to $2.5 \mathrm{D}$, Table 1 ).
The patients reported improved and more comfortable vision, and described themselves as being satisfied with the outcome. The patient who underwent the triple procedure (penetrating keratoplasty + extracapsular cataract extraction + intraocular lens) obtained good visual results (corrected distance visual acuity $0.2 \log$ MAR).

\section{Discussion}

Keratoconus is a progressive, bilateral, often asymmetrical, noninflammatory corneal ectasia. Currently available treatments for keratoconus (rigid contact lens, lamellar keratoplasty, corneal rings) largely involve interventions which are done for tectonic, optical, or refractive reasons. ${ }^{19}$ Unfortunately, none of these options treat the underlying cause of ectasia, and therefore cannot stop the progression of keratoconus. Corneal collagen cross-linking based on combined use of riboflavin as a photosensitizer and ultraviolet $\mathrm{A}$ light of $370 \mathrm{~nm}$ is the only available treatment directed at the underlying pathology in the keratoconic cornea, which is essentially stromal, biomechanical, and structural instability leading to progressive ectasia.



Figure 2 (Continued) 


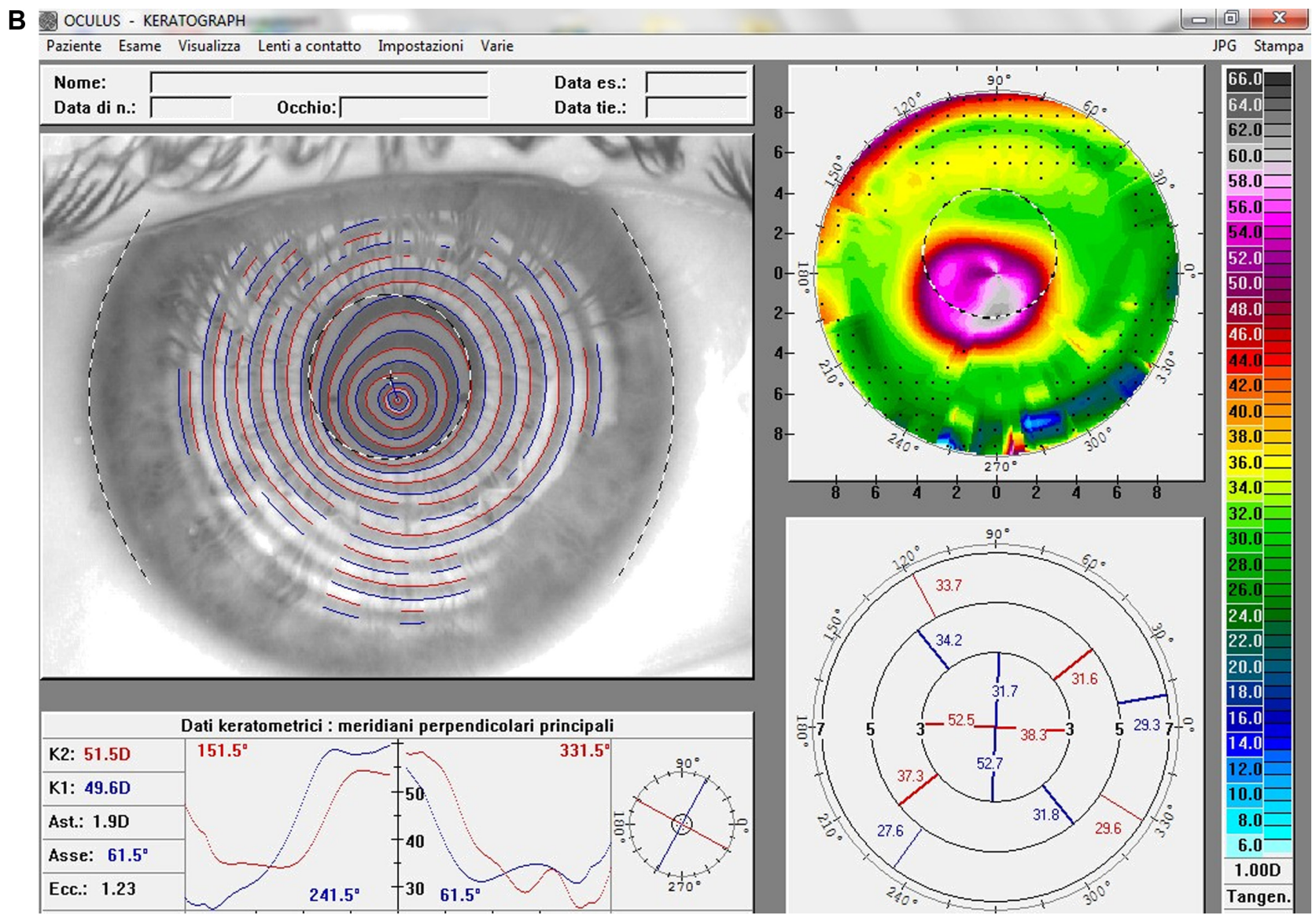

Figure 2 (A) Videokeratographic map of the right eye of a 19-year-old male patient before treatment. The topographic pattern highlights the keratoconus appearance. The apex of ectasia power (in the central side of the cornea) is 68.7 D (relative scale, tangential algorithm). (B) Right eye videokeratographic map I2 months after transepithelial corneal collagen cross-linking with riboflavin and ultraviolet $\mathrm{A}$ irradiation.

Note: The topographic pattern showed a slight improvement in corneal profile, and a reduction of the apex of ectasia power to $65.2 \mathrm{D}$ (relative scale, tangential algorithm).

Standard corneal CXL is limited to eyes with a corneal thickness of at least $400 \mu \mathrm{m}$ due to concerns about the cytotoxic effect on the corneal endothelium, crystalline lens, and other intraocular tissues. ${ }^{6,7}$ This is due to the fact that irradiance of $0.37 \mathrm{~mW} / \mathrm{cm}^{2}$ has been found to be cytotoxic to the endothelial cell layer. Because the absorption coefficient of the human cornea is $70 \mathrm{~cm}^{-1}$ and the intended surface irradiance is $3.0 \mathrm{~mW} / \mathrm{cm}^{2}$, the $0.37 \mathrm{~mW} / \mathrm{cm}^{2}$ irradiance is reached at a depth of $300 \mu \mathrm{m}$. In a 400-micron thick cornea saturated with riboflavin, irradiance at the endothelial level is $0.18 \mathrm{~mW} / \mathrm{cm}^{2}$, which is only $50 \%$ of the damage threshold. Therefore, the $400 \mu \mathrm{m}$ limit is considered to protect the endothelium and intraocular structures from the adverse effects of ultraviolet irradiation and has therefore been established as a clinical standard. ${ }^{20-22}$ In a recent publication, Kymionis et al reported a significant endothelial cell count loss postoperatively after standard CXL treatment in corneas with central pachymetry less than $400 \mu \mathrm{m} .{ }^{23}$ The $400 \mu \mathrm{m}$ threshold limits utilization of CXL in eyes with advanced corneal ectasia. ${ }^{6,7}$ Transepithelial CXL, ${ }^{8} \mathrm{CXL}$ with customized pachymetric-guided epithelial debridement preserving the epithelium in thinner corneal regions, ${ }^{9}$ and the concept of iatrogenic corneal swelling before CXL application ${ }^{10}$ have been developed as alternative techniques for thin corneas.

The theoretical basis for transepithelial CXL presents two major challenges: the role of the corneal epithelium as a barrier to ultraviolet A penetration and the difficulty of penetration by a hydrophilic macromolecule such as riboflavin through the corneal epithelium. The epithelium and Bowman's layer have significantly high absorption coefficients in the ultraviolet spectrum. The ultravioletfiltering ability of the epithelium may be due to its particular molecular composition, resulting in a high absorption coefficient. ${ }^{15}$ Riboflavin has a dual role in corneal collagen CXL, working as a photosensitizer for production of oxygen free radicals and inducing collagen cross-linking, mainly by carbonyl-based reactions that require singlet oxygen. ${ }^{24}$ In the absence of a photosensitizer, ultraviolet light at wavelengths 
of $350 \mathrm{~nm}$ and higher and an irradiance of $3 \mathrm{~mW} / \mathrm{cm}^{2}$ would not cause significant cytotoxicity. When riboflavin is combined with ultraviolet light exposure, the damage threshold is approximately 10 times less than that for ultraviolet light exposure alone $\left(0.35\right.$ versus $\left.4 \mathrm{~mW} / \mathrm{cm}^{2}\right) .{ }^{6}$ However, the shielding effect of riboflavin protects the underlying tissues from the deleterious consequences of concentration and absorbance of ultraviolet A. ${ }^{6,25}$ Appropriate distribution of riboflavin in the cornea is critically important, because failure to achieve adequate stromal absorption of riboflavin is likely to limit the CXL process and render the ocular tissues at risk of ultraviolet A damage. ${ }^{6,25}$

Riboflavin (molecular weight $376.37 \mathrm{~g} / \mathrm{mol}$ ) is a hydrophilic macromolecule which cannot penetrate intact epithelium. ${ }^{26}$ Although eyes with end-stage keratoconus often have a damaged basal epithelial layer and may behave differently in terms of barrier function compared with a normal healthy cornea, ${ }^{27}$ riboflavin/ultraviolet A corneal collagen CXL is typically only performed in eyes with mild to moderate ectasia in which the basal layer is intact. ${ }^{28} \mathrm{In}$ these eyes, a simple de-epithelialization procedure removes the diffusion barrier and speeds saturation of the riboflavin molecule in the corneal stroma. ${ }^{29}$

Some substances, like benzalkonium chloride, EDTA, and trometamol, especially when combined, enhance epithelial permeability of hydrophilic macromolecules. ${ }^{12-14,30-33}$ Some clinicians advocate the use of topical anesthetic tetracaine $1 \%$ in an attempt to loosen epithelial tight junctions. ${ }^{34}$ In our study, trometamol and sodium EDTA enhancers were used to facilitate epithelial penetration of riboflavin. Trometamol is a weakly toxic, biologically inert amino alcohol used in a wide variety of products including cosmetics, as an industrial buffer solution, and as a component of pharmaceuticals due to its intracellular and extracellular alkalizing action. Although widely used, sensitization to the product has rarely been reported (only a single case in which a gel containing trometamol was associated with periorbital dermatitis). As such, its safety profile is well established. ${ }^{35}$ EDTA breaks intercellular bonds, thus facilitating the penetration of various substances.

Performing CXL with the epithelium intact has been suggested to increase patient comfort ${ }^{11}$ and decrease the likelihood of complications, such as infectious keratitis, stromal haze, and corneal thinning and melting. ${ }^{36,37}$ However, an initial experimental study demonstrated the necessity for complete epithelial removal due to a lack of alteration of biomechanical properties of corneal tissue when the procedure was performed with intact epithelium. ${ }^{1}$ Additionally, in vitro, ex vivo, and in vivo studies of transepithelial CXL in animal models have shown that the procedure is not efficacious. ${ }^{11,38}$ In a clinical study of transepithelial CXL, no penetration of riboflavin in the anterior chamber was evident on slit-lamp examination; however, there was also no endothelial damage documented in that study. ${ }^{34}$ Similarly, comparison of light transmission spectra in porcine corneal stroma demonstrated that complete removal of the corneal epithelium is an essential component of the treatment, because superficial epithelial trauma or tetracaine administration alone in corneas with intact epithelium was not sufficient to permit penetration of riboflavin to achieve an adequate intrastromal concentration. ${ }^{34} \mathrm{~A}$ high-performance liquid chromatography study has also shown that the stromal concentrations of riboflavin increased with exposure time and reached a safe and effective concentration for the CXL procedure only if the epithelium was completely removed. ${ }^{11}$ Another experimental study of transepithelial CXL with topical anesthetics and benzalkonium chloride in living rabbits demonstrated a $21 \%$ increase in corneal rigidity versus a $102 \%$ increase in corneal rigidity when CXL with de-epithelialization was performed. It was estimated that this could translate into a $64 \%$ increase in corneal rigidity in human corneas with transepithelial CXL versus $320 \%$ using CXL with de-epithelialization. ${ }^{8}$ The endothelial safety of transepithelial CXL has been confirmed experimentally. ${ }^{8}$

In the present study, transepithelial CXL in 16 patients with advanced keratoconus induced a slight improvement in uncorrected and corrected distance visual acuity, manifest refraction, and apical keratometry, with no changes in preoperative versus postoperative endothelial cell density or morphology. This represents an important safety consideration in assessing the procedure, and was confirmed by immunohistochemical results showing normal expression of connexin-43 6 months after treatment as an index of well maintained epithelial and endothelial function, even in these very thin corneas. Keratocytes appeared to be regularly arranged and normally distributed throughout the stroma, as shown by CD-34 immunoreactivity. ${ }^{18}$

The average age of our patients was 34.4 years, at which time progression of keratoconus tends to wane or even stop. In fact, keratoconus generally manifests during adolescence through early adulthood. The cornea tends to stiffen naturally with age, and it has been hypothesized that age-related corneal stiffening explains the stabilization of the condition with advancing age. Nevertheless, keratoconus is diagnosed after the age of 40 years on approximately $4 \%-10 \%$ of occasions, and sometimes 
as late as 70 years. ${ }^{39}$ However, in the present study, the inclusion criteria included keratoconus with documented progression in the past 12 months.

In conclusion, transepithelial CXL using riboflavin with substances added to enhance epithelial permeability was safe and seemed to be moderately effective in keratoconic eyes with ultrathin corneas, and could be expanded to include use in patients with more advanced keratoconus. However, the efficacy of this technique in the long term needs to be assessed in the future with a greater number of patients.

\section{Acknowledgment}

The authors acknowledge the contribution to this study of the Department of Biotechnological and Applied Clinical Sciences, University of L'Aquila, L'Aquila, Italy.

\section{Disclosure}

The authors report no conflicts of interest in this work.

\section{References}

1. Spoerl E, Huhle M, Seiler T. Induction of cross-links in corneal tissue. Exp Eye Res. 1998;66:97-103.

2. Wollensak G, Spoerl E, Seiler T. Riboflavin/ultraviolet-A-induced collagen crosslinking for the treatment of keratoconus. Am J Ophthalmol. 2003;135:620-627.

3. Spadea L. Corneal collagen cross-linking with riboflavin and UVA irradiation in pellucid marginal degeneration. $J$ Refract Surg. 2010;26: 375-377.

4. Spadea L. Collagen crosslinking for ectasia following photorefractive keratectomy performed in excimer laser-assisted keratoplasty for keratoconus. Eur J Ophthalmol. 2012;22:274-277.

5. Spadea L, Cantera E, Cortes M, Evangelista Conocchia N, Stewart CW. Corneal ectasia after myopic laser in situ keratomileusis: a long term study. Clin Ophthalmol. 2012;6:1801-1813.

6. Spoerl E, Mrochen M, Sliney D, et al. Safety of UVA riboflavin crosslinking of the cornea. Cornea. 2007;26:385-389.

7. Wollensak G. Crosslinking treatment of progressive keratoconus: new hope. Curr Opin Ophthalmol. 2006;17:356-360.

8. Wollensak G, Iomdina E. Biomechanical and histological changes after corneal crosslinking with and without epithelial debridement. $J$ Cataract Refract Surg. 2009;35:540-546.

9. Kymionis GD, Diakonis VF, Coskunseven E, et al. Customized pachymetric guided epithelial debridement for corneal collagen cross linking. BMC Ophthalmol. 2009;9:10-14.

10. Hafezi F, Mrochen M, Iseli HP, Seiler T. Collagen crosslinking with ultraviolet-A and hypoosmolar riboflavin solution in thin corneas. $J$ Cataract Refract Surg. 2009;35:621-624.

11. Baiocchi S, Mazzotta C, Cerretani D, et al. Corneal crosslinking: riboflavin concentration in corneal stroma exposed with and without epithelium. J Cataract Refract Surg. 2009;35:893-899.

12. Chang SW, Chi RF, Wu CC, Su MJ. Benzalkonium chloride and gentamicin cause a leak in corneal epithelial cell membrane. Exp Eye Res. 2000;71:3-10.

13. Uematsu M, Kumagami T, Kusano M, et al. Acute corneal epithelial change after instillation of benzalkonium chloride evaluated using a newly developed in vivo corneal transepithelial electric resistance measurement method. Ophthalmic Res. 2007;39:308-314.
14. Nakamura T, Yamada M, Teshima M, et al. Electrophysiological characterization of tight junctional pathway of rabbit cornea treated with ophthalmic ingredients. Biol Pharm Bull. 2007;30: 2360-2364.

15. Bottós KM, Schor P, Dreyfuss JL, Nader HB, Chamon W. Effect of corneal epithelium on ultraviolet-A and riboflavin absorption. Arq Bras Oftalmol. 2011;74:348-351. Portuguese.

16. Raiskup-Wolf F, Hoyer A, Spoerl E, Pillunat LE. Collagen crosslinking with riboflavin and ultraviolet-a light in keratoconus: long term result. $J$ Cataract Refract Surg. 2008;34:796-801.

17. Spoerl E, Raiskup-Wolf F, Kuhlisch E, Pillunat LE. Cigarette smoking is negatively associated with keratoconus. $J$ Refract Surg. 2008;24: S737-S740.

18. Spadea L, Mencucci R. Corneal collagen cross-linking. Ophthalmology. 2011;118:2520. e1-e4.

19. Spadea L, Gizzi R, Evangelista Conocchia N, Urbano S. Optical pachimetry-guided customized excimer laser-assisted lamellar keratoplasty for the surgical treatment of keratoconus. $J$ Cataract Refract Surg. 2012;38:1559-1567.

20. Spoerl E, Wollensak G, Seiler T. Increased resistance of crosslinked cornea against enzymatic digestion. Curr Eye Res. 2004;29: $35-40$.

21. Wollensak G, Spoerl E, Wilsch M, Seiler T. Endothelial cell damage after riboflavin-ultraviolet-A-treatment in the rabbit. J Cataract Refract Surg. 2003;29:1786-1790.

22. Wollensak G, Spoerl E, Reber F, Seiler T. Keratocyte cytotoxicity of riboflavin/UVA treatment in vitro. Eye. 2004;18:718-722.

23. Kymionis GD, Portaliou DM, Diakonis VF, Kounis GA, Panagopoulou SI, Grentzelos MA. Corneal collagen cross-linking with riboflavin and ultraviolet-A irradiation in patients with thin corneas. Am J Ophthalmol. 2012;153:24-28

24. McCall AS, Kraft S, Edelhauser HF, et al. Mechanisms of corneal tissue cross-linking in response to treatment with topical riboflavin and long-wavelength ultraviolet radiation (UVA). Invest Ophthalmol Vis Sci. 2010;51:129-138.

25. Spoerl E, Wollensak G, Dittert DD, Seiler T. Thermomechanical behaviour of collagen-cross-linked porcine cornea. Ophthalmologica. 2004;218:136-140.

26. Rathore MS, Majumdar DK. Effect of formulation factors on in vitro transcorneal permeation of gatifloxacin from aqueous drops. AAPS Pharm Sci Tech. 2006;7:57.

27. Hollingsworth JG, Bonshek RE, Efron N. Correlation of the appearance of keratoconic cornea in vivo by confocal microscopy and in vivo by light microscopy. Cornea. 2005;24:397-405.

28. Samaras K, O'Brart DP, Doutch J, et al. Effect of epithelial retention and removal on riboflavin absorption in porcine corneas. $J$ Refract Surg. 2009;25:771-775.

29. Prausnitz MR, Noonan JS. Permeability of cornea, sclera and conjunctiva: a literature analysis for drug delivery to the eye. J Pharm Sci. 1998;87:1479-1488.

30. Majumdar S, Hippalgaonkar K, Repka MA. Effect of chitosan, benzalkonium chloride and ethylenediaminetetraacetic acid on permeation of acyclovir across isolated rabbit cornea. Int $J$ Pharm. 2008;348:175-178.

31. Koppen C, Wouters K, Mathysen D, Rozema J, Tassignon MJ. Refractive and topographic results of benzalkonium chloride-assisted transepithelial crosslinking. J Cataract Refract Surg. 2012;38: $1000-1005$.

32. Kikuchi T, Suzuki M, Kusai A, et al. Mechanism of permeabilityenhancing effect of EDTA and boric acid on the corneal penetration of 4-[1-hydroxy-1-methylethyl]-2-propyl-1-[4-[2-[tetrazole-5-yl]phenyl] phenyl] methylimidazole-5-carboxylic acid monohydrate (CS-088). Int J Pharm. 2005;299:107-114.

33. Pauly A, Meloni M, Brignole-Baudouin F, et al. Multiple endpoint analysis of the 3D-reconstituted corneal epithelium after treatment with benzalkonium chloride: early detection of toxic damage. Invest Ophthalmol Vis Sci. 2009;50:1644-1652. 
34. Hayes S, O'Brart DP, Lamdin LS, et al. Effect of complete epithelial debridement before riboflavin-ultraviolet-A corneal collagen crosslinking therapy. J Cataract Refr Surg. 2008;34:657-661.

35. Nahas GG, Sutin KM, Fermon C, et al. Guidelines for the treatment of acidaemia with THAM. Drugs. 1998;55:191-224.

36. Leccisotti A, Islam T. Transepithelial corneal collagen crosslinking in keratoconus. J Refract Surg. 2010;26:942-948.

37. Filippello M, Stagni E, O'Brart D. Transepithelial corneal collagen crosslinking: bilateral study. J Cataract Refract Surg. 2012;38: 283-291.
38. Wollensak G, Spoerl E, Seiler T. Stress-strain measurements of human and porcine corneas after riboflavin/ultraviolet induced cross-linking. $J$ Cataract Refract Surg. 2003;29:1780-1785.

39. Yildiz E, Diehl GF, Cohen EJ, Hammersmith KM, Laibson PR, Rapuano CJ. Demographics of patients older than 50 years with keratoconus. Eye Contact Lens. 2009;35:309-311.
Clinical Ophthalmology

\section{Publish your work in this journal}

Clinical Ophthalmology is an international, peer-reviewed journal covering all subspecialties within ophthalmology. Key topics include: Optometry; Visual science; Pharmacology and drug therapy in eye diseases; Basic Sciences; Primary and Secondary eye care; Patient Safety and Quality of Care Improvements. This journal is indexed on

\footnotetext{
Submit your manuscript here: http://www.dovepress.com/clinical-ophthalmology-journal
}

\section{Dovepress}

PubMed Central and CAS, and is the official journal of The Society of Clinical Ophthalmology (SCO). The manuscript management system is completely online and includes a very quick and fair peer-review system, which is all easy to use. Visit http://www.dovepress.com/ testimonials.php to read real quotes from published authors. 